\title{
Effects of GM-CSF and M-CSF on tumor progression of lung cancer: Roles of MEK1/ERK and AKT/PKB pathways
}

\author{
YOSHIKI UEMURA, MAKOTO KOBAYASHI, HIDESHI NAKATA, TETSUYA KUBOTA, \\ KENTARO BANDOBASHI, TSUYAKO SAITO and HIROKUNI TAGUCHI
}

\author{
Department of Internal Medicine, Kochi Medical School, Kohasu, Okocho, Nankoku, Kochi 783-8505, Japan
}

Received February 23, 2006; Accepted April 18, 2006

\begin{abstract}
Several studies have demonstrated that colonystimulating factors (CSFs) are closely associated with tumor progression, metastasis and invasion through autocrine or paracrine mechanism in lung cancer. However, biologic roles of CSFs are still unknown. Elucidating the biologic roles of CSFs and the regulatory mechanisms of tumor-specific behavior by CSFs raises the possibility of having a new therapeutic approach for lung cancer. We previously established two adenocarcinoma cell lines, A924 and A964 and a large cell carcinoma cell line MI-4. MI-4 and A924 constitutively produced an abundant dose of granulocyte macrophage colony-stimulating factor (GM-CSF) and macrophage colony-stimulating factor (M-CSF). We examined the effects of GM-CSF and M-CSF on tumor growth, death, and invasion in CSF-producing (A924 and MI-4) and non-producing lung cancer cells (A549 and A964). These cell lines demonstrated both GM-CSF and MCSF receptor mRNA expression. In our study, GM-CSF seemed to have advantage for tumor proliferation and invasion in lung cancer cells. M-CSF seemed to have advantage for tumor invasion, but not proliferation. The tumor-specific phenotypes (proliferation, invasion and survival) up-regulated by GM-CSF and M-CSF were mediated through MEK/ERK and PI3k/Akt pathways. However, when MEK/ERK was activated by transfection of active form of $M E K 1 \mathrm{cDNA}$, the tumor-specific behavior was promoted in CSF-non-producing cells, whereas inhibited in CSF-producing cells though MEK/ERK activation increased constitutive GM-CSF production. MEK/ERK signaling regulated differently tumor-specific behavior between CSFproducing cells and CSF-non-producing cells.
\end{abstract}

Correspondence to: Dr Yoshiki Uemura, Department of Internal Medicine, Kochi Medical School, Kohasu, Okocho, Nankoku, Kochi 783-8505, Japan

E-mail: uemuray@med.kochi-u.ac.jp

Key words: granulocyte macrophage colony-stimulating factor, macrophage colony-stimulating factor, MEK/ERK, PI3K/PKB $\alpha$, lung cancer

\section{Introduction}

In advanced clinical stages, many cases of lung cancer constitutively produce colony-stimulating factors (CSFs), including granulocyte colony-stimulating factor (G-CSF), granulocyte-macrophage colony-stimulating factor (GM-CSF), and macrophage colony-stimulating factor (M-CSF) in amounts large enough to cause a significant systemic hematopoietic effect (1-3). Although biologic properties of the overproduction of CSFs by tumor cells are still largely unknown, the prognosis is significantly worse in patients with non-small cell lung cancer (NSCLC) showing G-CSF gene expression (4). Mroczko et al demonstrated that CSFs could be useful in diagnostics and monitoring of NSCLC (5). Some studies show that CSFs produced by lung cancer cells might promote tumor progression through an autocrine mechanism $(6,7)$. Exogenous CSFs also promote invasion by lung cancer cells through the enhanced production of extracellular matrixdegrading proteinases by the tumor cells or prolong tumor cell survival $(8,9)$. Thus, CSFs seem to be closely associated with tumor progression through an autocrine or paracrine mechanism in lung cancer. To consider new therapeutic approaches to lung cancer, it is important to clarify the effect of CSFs on tumor progression and the signaling pathways activated by CSFs.

The mitogen-activated protein kinase (MAPK) pathway has been shown to be relevant in human carcinogenesis $(10,11)$. Activation of extracellular signal regulated kinase (ERK) has been reported in tumors of the lung (12), kidney (13), breast (14), head and neck (15), liver (16), prostate (17), salivary gland (18), and skin (19). Constitutive MEK1 activation contributes to cell survival, migration, and transformation of fibroblasts and epithelial cells (20-22). ML-1 [interleukin $17 \mathrm{~F}$ (IL-17F)] induces GM-CSF expression through the activation of the Raf1-MEK-ERK $1 / 2$ pathway in normal human bronchial epithelial cells (23). Up-regulation of the ERK pathway is one mechanism induced by M-CSF and IL-3 to protect myeloid progenitors from the growth-suppressive and apoptosis-inducing effects of cyclic adenosine monophosphate (cAMP) elevations (24). The phosphatidylinositol-3 kinase (PI3K)/Akt signaling pathway also plays an important role in cell proliferation, apoptosis, angiogenesis, adhesion, invasion, and migration, functions that are critical to cancer cell survival and metastasis (25). M-CSF induces cell survival through Akt-induced suppression of caspase-9 activation (26). 
These findings prompted us to determine whether CSFs might have an effect on tumor progression through the signaling pathway of MEK/ERK or PI3K/Akt.

Some studies demonstrate the autocrine growth mechanism of G-CSF (27). GM-CSF (28), or M-CSF (29) in lung cancer. However, most of G-CSF-producing tumors have few G-CSF receptors (30). Based on this fact, it is difficult to discern the biologic meaning of G-CSF in lung cancer. Therefore, in this study, we focused on the effects of GM-CSF and M-CSF. Our data show that GM-CSF and M-CSF were able to regulate tumor growth and invasion through the signaling pathway of MEK/ ERK or PI3K/Akt.

\section{Materials and methods}

Reagent and supplies. Enzyme-linked immunosorbent assay (ELISA) kits for measuring the contents of GM-CSF in culture medium were from TECHNE (Minneapolis, MN) and M-CSF from R\&D Systems (Minneapolis, MN). The extracellular matrix (ECM) cell invasion assay kit was obtained from Chemicon (Temecula, CA). Recombinant human GM-CSF was obtained from Sigma (St. Louis, MO) and recombinant human M-CSF from Kyowa Hakko (Chiyodaku, Tokyo). Rabbit anti-Myc tag and rabbit anti-HA tag antibodies were purchased from Upstate Biotechnology (Lake Placid, NY). Rabbit anti-phospho-p44/42 MAPK, rabbit anti-phosphoAkt1, rabbit anti-Erk2, rabbit anti-Akt antibodies were purchased from Cell Signaling Technology (Beverly, MA). The 'Cell Titer 96' AQueous one solution cell proliferation assay kit and 'Cyto Tox 96' non-radioactive cytotoxicity assay kit were purchased from Promega (Madison, WI). MiraClean endotoxin removal kit (Mirus, WI) and TransIT ${ }^{\circledR}$-LT1 transfection reagent were obtained from Mirus (Madison, WI). Active forms of human $M E K 1$ and $A k t 1 / P K B \alpha \mathrm{cDNA}$, dominant negative (DN) mutant of $A k t 1 / P K B \alpha \mathrm{cDNA}$ and empty expression vector pUSEamp (+) were purchased from Upstate Biotechnology. PD98059 was purchased from Calbiochem (San Diego, CA). LY29004 was purchased from Promega. PD98059 and LY29004 were prepared with dimethyl sulphoxide (DMSO) as 1000X stock and were handled in subdued light conditions.

Cell culture. The A924, A964 and MI-4 (31) lines were previously established from lung cancer cells in our laboratory. The A924 and A964 lines were derived from the patients with adenocarcinoma and MI-4 was from large-cell carcinoma. The three lung cancer cell lines and adenocarcinoma cell line A549 (American Type Culture Collection, Rockville, MD) were maintained in RPMI-1640 medium containing 10\% fetal calf serum (FCS) at $37^{\circ} \mathrm{C}$ in an incubator, under a $100 \%$ humidified $5 \% \mathrm{CO}_{2}$ atmosphere. Subcultures were carried out twice weekly by removing the cells from $75-\mathrm{cm}^{2}$ tissue flasks with $0.025 \%$ trypsin in $0.02 \%$ ethylene diaminetetraacetic acid and splitting them 1:3. For experiments, all cultures were grown to confluence in $25-\mathrm{cm}^{2}$ tissue flasks or 96 -well plates in the presence of $10 \%$ FCS.

Plasmids and DNA transfection. The active Akt1 or DN Akt1 cDNA contained a Myc-His tag at the 3' end of the Akt1 open reading frame. The active $M E K 1 \mathrm{cDNA}$ contained a HA tag. DNA transfection was carried out using TransIT-LT1 transfection reagent. Subconfluent cells in a $60-\mathrm{mm}$ tissue culture dish were transfected with $5 \mu \mathrm{g}$ DNA in the presence of $15 \mu \mathrm{l}$ of TransIT-LT1 transfection reagent in $2 \mathrm{ml}$ of media containing 5\% FCS. At $48 \mathrm{~h}$ after transfection, cells were harvested then used for each experiment. Expression of Akt1 was detected by immunoblot analysis of cells transfected with activated or DN Aktl cDNA using anti-Myc tag antibody, and MEK1 with activated $M E K 1$ cDNA using anti-HA tag antibody.

Detection of GM-CSF and M-CSF. The concentration of GM$\mathrm{CSF}$ or M-CSF in the culture medium was determined using an ELISA kit according to the supplier's instructions. The sensitivities for these kits are 3.0 and $9.0 \mathrm{pg} / \mathrm{ml}$ for GM-CSF and M-CSF, respectively. The values of GM-CSF and M-CSF in the conditioned medium are expressed in $\mathrm{pg} / 10^{6}$ cells. The GM-CSF or M-CSF level in the fresh medium was deducted from an actual measurement.

Western blot analysis. The medium was removed, and cell monolayers were washed 3 times with ice-cold phosphatebuffered saline (PBS) and lysed in ice-cold buffer [50 mM Tris-buffered saline ( $\mathrm{pH} 8.0), 150 \mathrm{mM} \mathrm{NaCl}, 0.002 \%$ sodium azide, $0.1 \%$ sodium dodecyl sulfate (SDS), $100 \mu \mathrm{g} / \mathrm{ml}$ phenylmethylsulfonyl fluoride, $10 \mu \mathrm{g} / \mathrm{ml}$ leupeptin, $10 \mu \mathrm{g} / \mathrm{ml}$ pepstatin, $1 \mu \mathrm{g} / \mathrm{ml}$ aprotinin, $200 \mathrm{mM}$ sodium orthovanadate, $1 \%$ (octylphenoxy) polyethoxyethanol, and $0.5 \%$ sodium deoxycholate] for $20 \mathrm{~min}$ on ice, followed by centrifugation at $4^{\circ} \mathrm{C}$ for $5 \mathrm{~min}$ to sediment the particulate material. The protein concentration of the supernatant was measured by a Bradford assay (Bio-Rad, Hercules, CA). Then, $10 \mu \mathrm{g}$ protein was separated on $10 \%$ SDS-polyacrylamide gels and transferred onto nitrocellulose membranes (Bio-Rad). The membrane was blocked overnight at $4{ }^{\circ} \mathrm{C}$ using I-block (Tropix, Bedford, MA). Membranes were incubated with 1:2000 dilutions of rabbit polyclonal antibody as described above. Chemiluminescence was determined using the Western-Star kit (Tropix, Foster City, CA), according to the manufacturer's instructions. Phosphorylation levels of Akt and p44/42 were quantified by densitometry (Bio-Rad).

$R T-P C R$. Total RNA was extracted from the cultured cells by the guanidine-thiocyanate method using Isogen solution (Nippon Gene, Tokyo, Japan). RNA (1 $\mu \mathrm{g}$ ) was converted to cDNA with Molony murine leukemia virus reverse transcriptase (RT) in $20 \mu 1$ of reaction mixture. For quantification, $1 \mu \mathrm{l}$ aliquots of cDNA samples were subjected to polymerase chain reaction (PCR) in $50 \mu 1$ of reaction solution containing $0.5 \mu \mathrm{M}$ of each specific primer, $10 \mathrm{mM}$ Tris- $\mathrm{HCl}, 50 \mathrm{mM} \mathrm{KCl}$, $1.5 \mathrm{mM} \mathrm{MgCl}_{2}, 0.2 \mathrm{mM} \mathrm{dNTP}$, and 1 unit Taq polymerase. The GM-CSF receptor $\alpha$ 546-bp fragment was detected by PCR $\left(30\right.$ cycles at $94^{\circ} \mathrm{C}$ for $1 \mathrm{~min}, 60^{\circ} \mathrm{C}$ for $1 \mathrm{~min}$, and $72^{\circ} \mathrm{C}$ for $1 \mathrm{~min}$ ) with 5'-CTTCTCTCTGACCAGCA-3' (forward primer) and 5'-ACATGGGTTCCTGAGTC-3' (reverse primer). The M-CSF (CSF-1) receptor 360-bp fragment was detected by PCR $\left(30\right.$ cycles at $94^{\circ} \mathrm{C}$ for $1 \mathrm{~min}, 61^{\circ} \mathrm{C}$ for $1 \mathrm{~min}$, and $72^{\circ} \mathrm{C}$ for $1 \mathrm{~min}$ ) with $5^{\prime}$-TCCAACTACATTGTCAAG GGCAATGCCCGCCT-3' (forward primer) and 5'-CAGAT TGGTATAGTCCCGCTCTCTCCTGTCCT-3' (reverse 


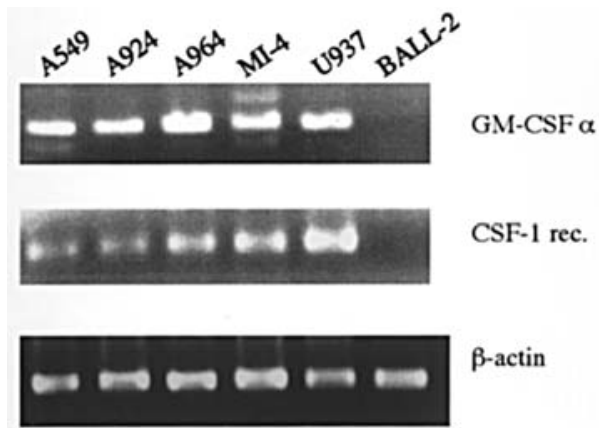

Figure 1. Expression of GM-CSF $\alpha$ receptor and CSF-1 receptor mRNA in A549, A924, A964 and MI-4 cells. U937 cells and BALL-2 cells were used as a positive control and a negative control for the receptors, respectively. Results are representative of three independent experiments.

primer). The 3 -actin 309-bp fragment was detected by PCR (20 cycles at $94^{\circ} \mathrm{C}$ for $1 \mathrm{~min}, 58^{\circ} \mathrm{C}$ for $1 \mathrm{~min}$, and $72^{\circ} \mathrm{C}$ for $1 \mathrm{~min}$ ) with 5'-ACCTTCAACACCCCAGCCATG-3' (forward primer) and 5'-GGCCATCTCTTGCTCGAAGTC-3' (reverse primer). PCR product $(1 \mu \mathrm{g})$ was electrophoresed on $1 \%$ NuSieve GTG agarose gel and stained with ethidium bromide. U937 cells were used as positive controls for the mRNA expression of both receptors and BALL-2 cells negative controls. The identity of the PCR amplification products was confirmed by size and restriction digest. The intensity of the bands was evaluated using a UV-light box imaging system (Atto, Tokyo, Japan).

Cell proliferation and cytotoxicity assay. Cells $\left(1 \times 10^{5}\right)$ were plated in 96-well plates and then cultured in the serum-free medium for $24 \mathrm{~h}$ to deprive them of FCS. The medium was changed to a new one containing several ranges of GM-CSF $(0-100 \mu \mathrm{g} / \mathrm{ml})$ and M-CSF $\left(0-10^{4} \mathrm{IU} / \mathrm{ml}\right)$. After $48 \mathrm{~h}$ of incubation, cell proliferation assay was performed using the 'Cell Titer 96' AQueous one solution cell proliferation assay kit (Promega). Released lactate dehydrogenase (LDH) in culture supernatants was measured using 'Cyto Tox 96' cytotoxicity assay kit (Promega). The absorbance of the solution was measured at $490 \mathrm{~nm}$ in a spectrophotometer. The data represent the mean $\pm \mathrm{SE}$ of four wells from three independent experiments.

Invasion assay. Invasiveness was measured by use of a cell invasion assay kit. Before seeding, cells were starved in serum-free medium for $24 \mathrm{~h}$ and subsequently incubated with RPMI-1640 plus $10 \%$ NuSerum in the presence of various concentrations of GM-CSF and M-CSF for another $24 \mathrm{~h}$. NuSerum replaced FCS in the invasion assay because it contains standardized growth factors and fewer protease inhibitors. Cells were removed from the cell culture flask and suspended in NuSerum at a concentration of $1 \times 10^{5}$ cells $/ \mathrm{ml}$. A $300 \mu 1$ volume of cell suspension was placed in the upper wells. Lower wells were filled with $500 \mu 1$ of RPMI-1640 supplemented with $10 \%$ NuSerum and the plates were incubated for $48 \mathrm{~h}$. Invasive cells on the lower surface of the membrane were dyed blue according to the instructions, then dissolved in $10 \%$ acetic acid. The absorbance of the solution was measured at $560 \mathrm{~nm}$ in a spectrophotometer. The data
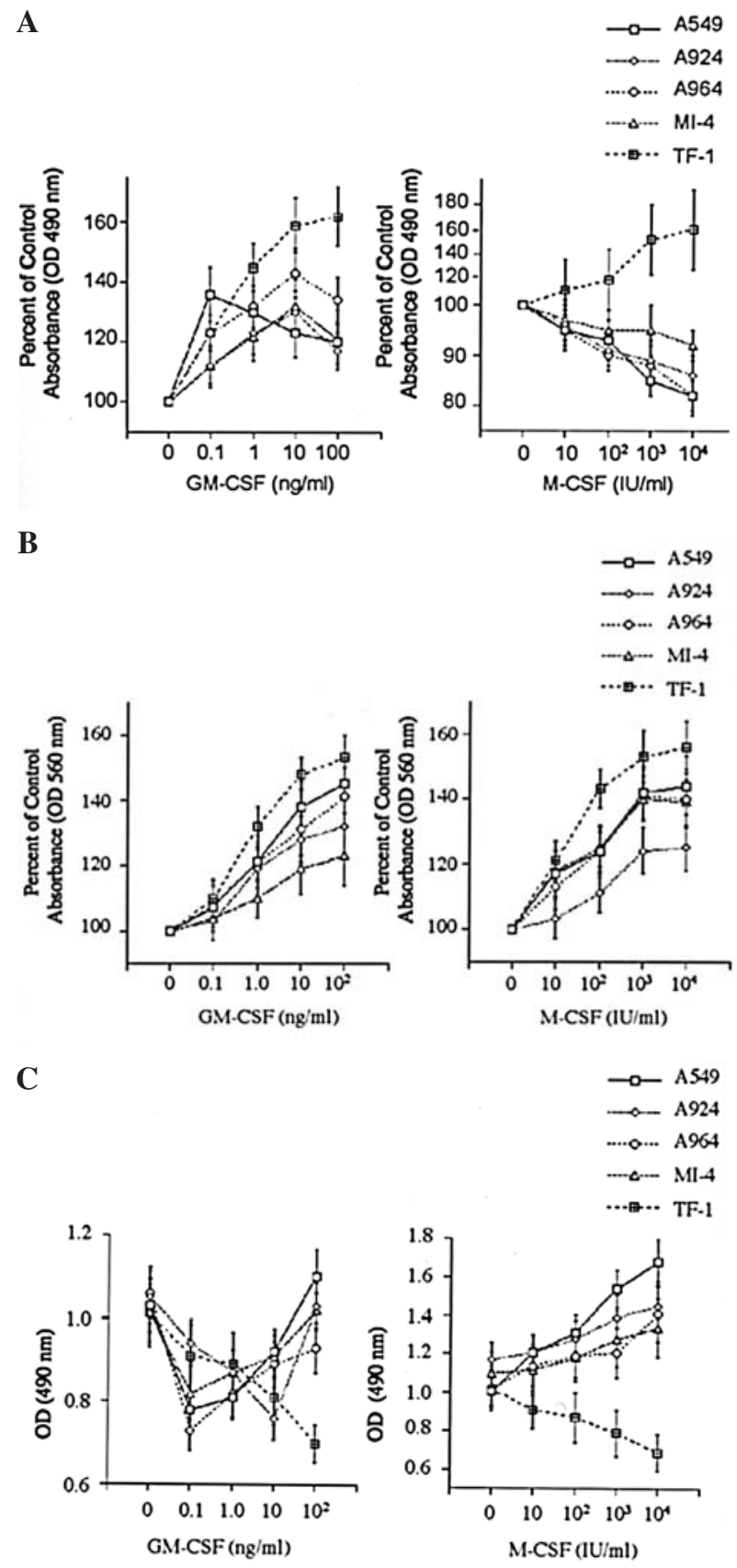

Figure 2. Effects of GM-CSF and M-CSF on cell growth, invasiveness and death. Cells were incubated with GM-CSF $\left(0-10^{2} \mathrm{ng} / \mathrm{ml}\right)$ or M-CSF $\left(0-10^{4} \mathrm{IU} / \mathrm{ml}\right)$ in the medium not containing FCS for $48 \mathrm{~h}$. TF- 1 cells, which depend on GM-CSF or M-CSF, were used as positive controls. (A) Cell proliferation assay was performed using 'Cell Titer 96' AQueous one solution cell proliferation assay kit. The absorbance of the solution was measured at $490 \mathrm{~nm}$ in a spectrophotometer. (B) Invasiveness was measured by use of a cell invasion assay kit. The absorbance of the solution was measured at $560 \mathrm{~nm}$ in a spectrophotometer. (C) Released LDH in culture supernatants was measured using 'Cyto Tox 96' cytotoxicity assay kit. The absorbance of the solution was measured at $490 \mathrm{~nm}$ in a spectrophotometer. Results are given as the mean percentage $( \pm 1 \mathrm{SE})$ of the absorbance in each control.

represent the mean $\pm \mathrm{SE}$ of four wells from three independent experiments.

Statistics. Values are presented as mean \pm SE. The unpaired $\mathrm{t}$-test was used to determine the statistical differences. For all analyses, a value of $\mathrm{P}<0.05$ was considered significant. 
A

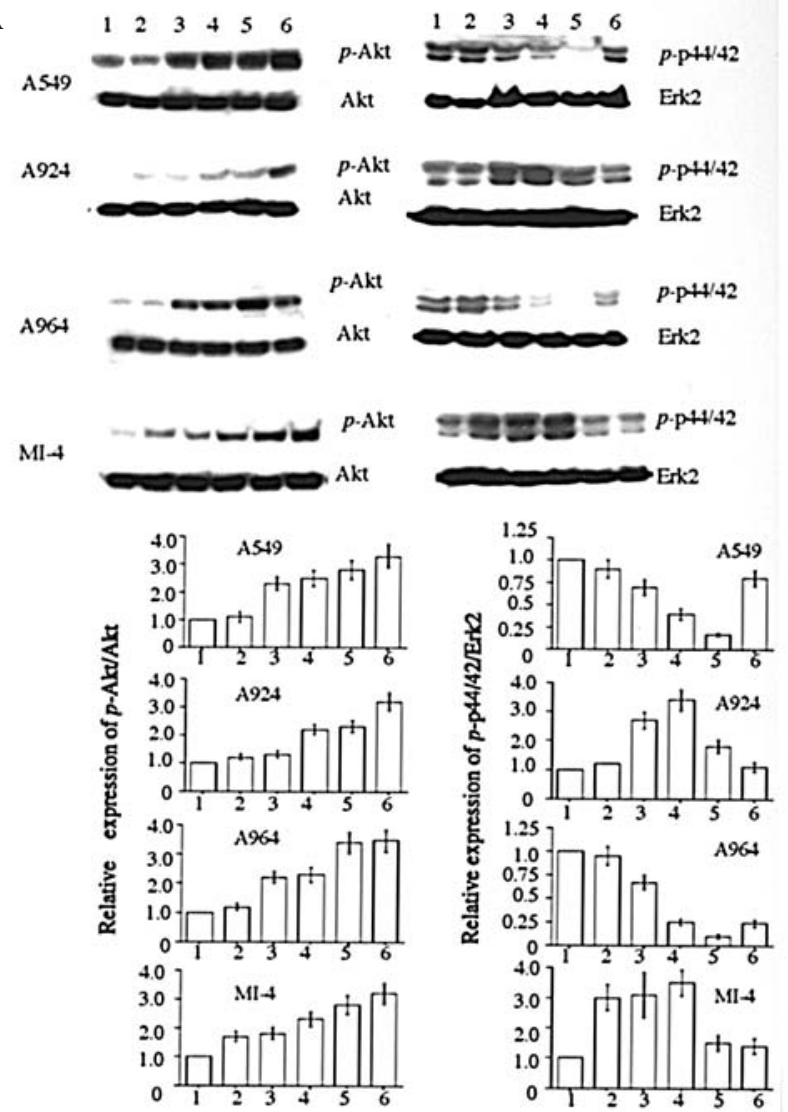

B

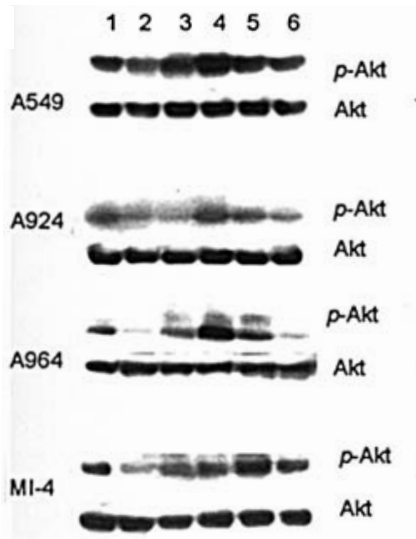

$\begin{array}{llllll}1 & 2 & 3 & 4 & 5 & 6\end{array}$

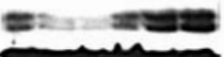

p.p44/42

Erk2
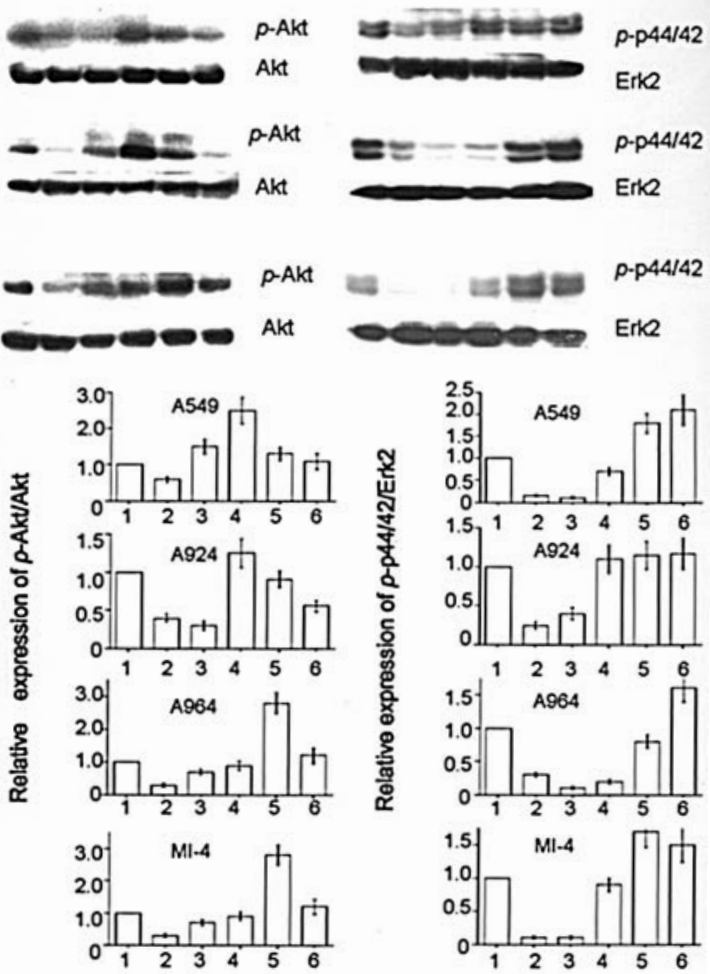

Figure 3. Effects of GM-CSF and M-CSF on the expression of $p$-Akt, Akt, $p$-p44/42 and Erk2. The effects of (A) GM-CSF (1.0 ng/ml) and (B) M-CSF (10² IU/ ml) on the phosphorylation of ERK1/2 and Akt were analyzed by Western blot analysis. Cells were harvested at the time points of 0 min (lane 1), 1 min (lane 2), $5 \mathrm{~min}$ (lane 3), $20 \mathrm{~min}$ (lane 4), $40 \mathrm{~min}$ (lane 5) and $24 \mathrm{~h}$ (lane 6). Cell lysates were then prepared, and Western blot analysis was performed. Phosphorylation levels of Akt and p44/42 were quantified by densitometry. The experiment was repeated 3 times and this is a representative example.

\section{Results}

Expression of GM-CSF and M-CSF (CSF-1) receptor $m R N A$ in lung cancer cell lines. Thel lung cancer cell lines A549, A924, A964 and MI-4 simultaneously expressed GM-CSF and M-CSF receptor mRNA (Fig. 1). U937 cells were used as positive controls for the receptors and BALL-2 as negative control. Results are representative of three independent experiments.

Effects of GM-CSF and M-CSF on cell growth, death and invasion in the cancer cells. For the evaluation of sensitivity to GM-CSF or M-CSF, a cell proliferation assay was performed using 'Cell Titer 96' AQueous one solution cell proliferation assay kit (Fig. 2A). Cells $\left(1 \times 10^{5}\right)$ were plated in 96-well plates and cultured for $48 \mathrm{~h}$ in the serum-free medium to deprive them of FCS. The cells were exposed continuously for $48 \mathrm{~h}$ to a range of concentration of GM-CSF or M-CSF in the serum-free medium. The absorbance of the solution was measured at $490 \mathrm{~nm}$ in a spectrophotometer. GM-CSF dose dependently stimulated the cell growth at $0.1-10 \mathrm{ng} / \mathrm{ml}$ in the cell lines. It maximally stimulated the cell growth at a low dose $(0.1 \mathrm{ng} / \mathrm{ml})$ in A549. M-CSF dose-dependently decreased the cell growth in the cell lines. MI-4 cells seemed to have a poor response to M-CSF. Invasiveness was measured by use of a cell invasion assay kit (Fig. 2B). The absorbance of the solution was measured at $560 \mathrm{~nm}$ in a spectrophotometer. GM-CSF and M-CSF promoted invasion in a dose-dependent manner. The invasiveness of A549, A924, A964, and MI-4 cells was $<0.1 \%$ in the absence of CSFs. Released LDH in culture supernatants was measured using 'Cyto Tox 96' cytotoxicity assay kit (Fig. 2C). The absorbance of the solution was measured at $490 \mathrm{~nm}$ in a spectrophotometer. GM-CSF efficiently reduced the OD levels at $0.1-10 \mathrm{ng} / \mathrm{ml}$ in the cell lines. GM-CSF maximally reduced the OD levels at $0.1 \mathrm{ng} / \mathrm{ml}$ in A549, A964, and MI-4 cells and at $10 \mathrm{ng} / \mathrm{ml}$ in A924 cells. M-CSF dose-dependently increased the OD levels by $10^{4} \mathrm{IU} / \mathrm{ml}$ in the cell lines. TF- 1 cells (ATCC CRL-2003), which depend on GM-CSF or M-CSF, were used as positive controls. Three independent experiments were carried out in quadruplicate.

Effects of GM-CSF and M-CSF on activation of PI3K/Akt and MEK/ERK signaling pathways. We evaluated the effect of GM-CSF and M-CSF on the phosphorylation of ERK1/2 and Akt by Western blot analysis. Cells were plated in 6-well plates then cultured in the serum-free medium to deprive FCS. After a $24 \mathrm{~h}$ culture, cells were incubated with $1.0 \mathrm{ng} / \mathrm{ml}$ GM-CSF or $10^{2} \mathrm{IU} / \mathrm{ml} \mathrm{M}-\mathrm{CSF}$. Cells were harvested at several time points $(0,1,5,20$, and $40 \mathrm{~min}$ and $24 \mathrm{~h})$. GMCSF time-dependently stimulated the phosphorylation of Akt in the cell lines. GM-CSF stimulated the phosphorylation of 
A
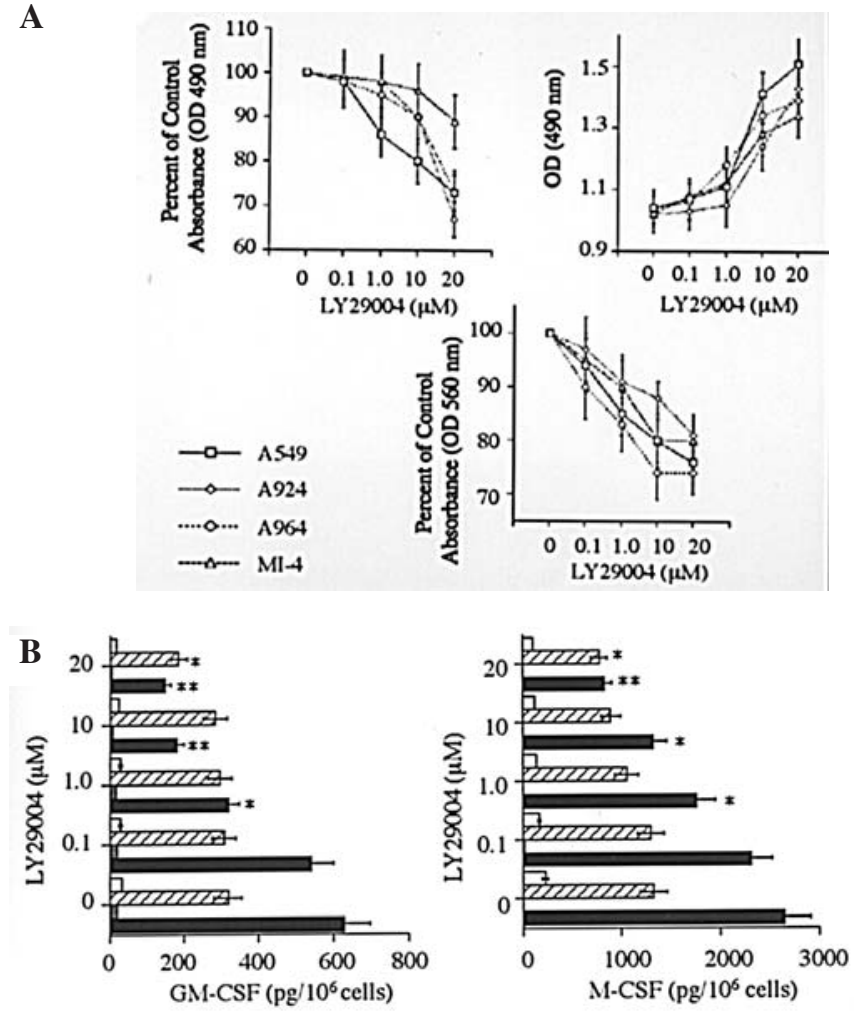

$\square$ A549

घ $\mathrm{A} 924$

ㅁ964

口 MI-4

Figure 4. Effects of PI3K inhibitor LY29004 on cell growth, cell death, invasion and CSF production. Serum-deprived cells were treated with several ranges of LY29004 $(0-20 \mu \mathrm{M})$ for $48 \mathrm{~h}$. (A) Cell proliferation, cytotoxicity and invason assays were performed. (B) GM-CSF and M-CSF levels in the medium were measured. The values of GM-CSF and M-CSF in the conditioned medium were expressed in $\mathrm{pg} / 10^{6}$ cells. Three independent experiments were carried out in quadruplicate. ${ }^{*} \mathrm{P}<0.05$ vs. control $(0 \mu \mathrm{M})$. ${ }^{* *} \mathrm{P}<0.01$ vs. control $(0 \mu \mathrm{M})$.

p44/42 in A924 and MI-4 cells. The maximal expression of $p$ p44/42 was detected at $20 \mathrm{~min}$ in the cell lines. GM-CSF timedependently suppressed the phosphorylation of p44/42 in A549 and A964 cells. Recovery of the expression of $p$ p44/42 was detected after $24 \mathrm{~h}$ in the cell lines (Fig. 3A). MCSF immediately inhibited the phosphorylation of Akt in the cells, then gradually increased it. The maximal expression of p-Akt was detected at 20-40 min. M-CSF time-dependently inhibited the phosphorylation of p44/42 in the cell lines. Recovery of the expression of $p$-p44/42 was detected at 2040 min (Fig. 3B). Phosphorylation levels of Akt and p44/42 were quantified by densitometry. Results are representative of three independent experiments.

Effects of PI3-K inhibitor LY29004 on cell growth, death, invasion and CSF production. LY29004 dose-dependently inhibited cell growth and invasion at a range of $0-20 \mu \mathrm{M}$ in the cell lines although effects of LY29004 were slight in MI-4. LY29004 dose-dependently increased cell death in the cell lines (Fig. 4A). MI-4 and A924 cells constitutively produced a large amount of GM-CSF and M-CSF. A549 and A964 cells
A

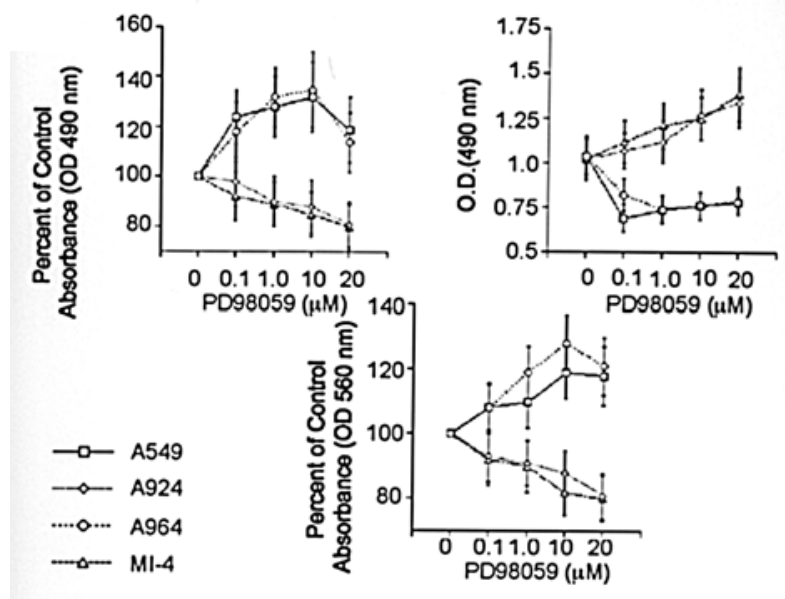

B
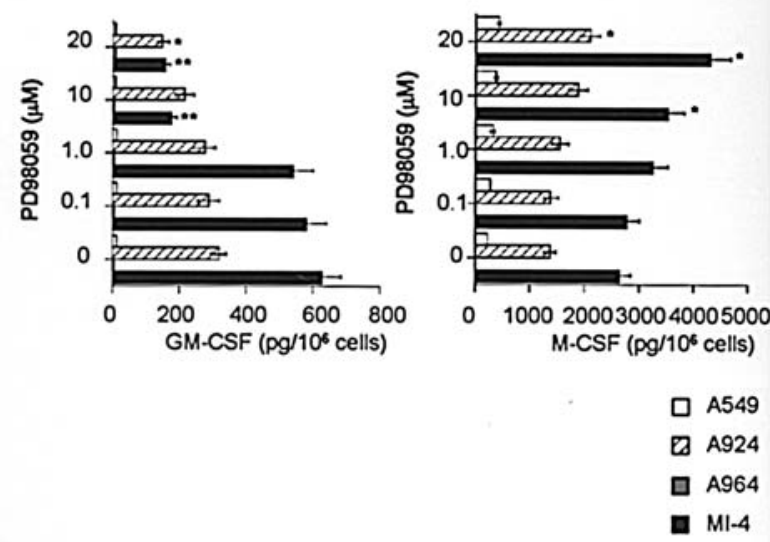

Figure 5. Effects of MEK 1 inhibitor PD98059 on cell growth, cell death, invasion and CSF production. Serum-deprived cells were treated with several range of PD98059 $(0-20 \mu \mathrm{M})$. (A) Cell proliferation, cytotoxicity and invasion assays were performed. (B) GM-CSF and M-CSF levels in the medium were measured. The values of GM-CSF and M-CSF in the conditioned medium were expressed in $\mathrm{pg} / 10^{6}$ cells. Three independent experiments were carried out in quadruplicate. ${ }^{*} \mathrm{P}<0.05$ vs. control $(0 \mu \mathrm{M})$. ${ }^{* *} \mathrm{P}<0.01$ vs. control $(0 \mu \mathrm{M})$.

scarcely produced CSFs. LY29004 dose-dependently decreased GM-CSF levels in MI-4 cells. LY29004 decreased GM-CSF levels only slightly at a high dose $(20 \mu \mathrm{M})$ in A924 cells. LY29004 dose-dependently decreased M-CSF levels in MI-4 and A924 cells (Fig. 4B). Three independent experiments were carried out in quadruplicate.

Effects of MEK 1 inhibitor PD98059 on cell growth, death, invasion and CSF production. PD98059 dose-dependently increased cell growth and invasion at a range of $0-10 \mu \mathrm{M}$ in A549 and A964 cells but decreased these parameters dosedependently at 0-20 $\mu \mathrm{M}$ in A924 and MI-4 cells. PD98059 dose-dependently increased cell death in A924 and MI-4 cells, but decreased cell death even at a low dose (0.1-1.0 $\mu \mathrm{M})$ in A549 and A964 cells (Fig. 5A). PD98059 dose-dependently decreased GM-CSF levels in A924 and MI-4 cells, but dose-dependently increased M-CSF levels (Fig. 5B). Three independent experiments were carried out in quadruplicate.

Effects of GM-CSF and M-CSF on the cells treated with LY29004. Cells were treated with $1.0 \mathrm{ng} / \mathrm{ml} \mathrm{GM-CSF}$ or $10^{2}$ 

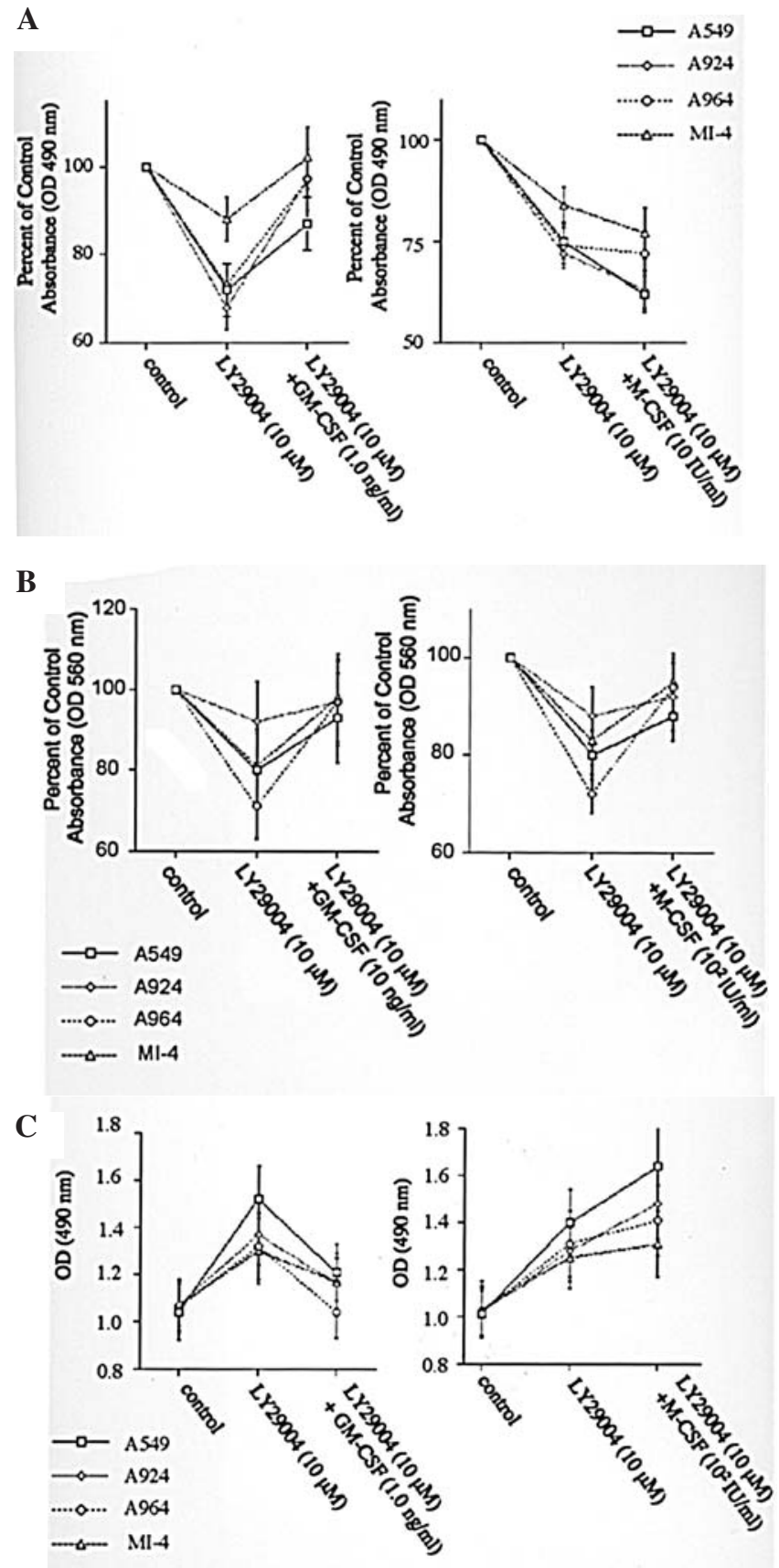

Figure 6. Effects of GM-CSF and M-CSF on the cells treated with LY29004. Cells were treated with $1.0 \mathrm{ng} / \mathrm{ml}$ of GM-CSF or $10^{2} \mathrm{IU} / \mathrm{ml}$ of $\mathrm{M}$-CSF for $24 \mathrm{~h}$ subsequently with $10 \mu \mathrm{M}$ of LY29004. After $48 \mathrm{~h}$, the effects of LY29004 on (A) proliferation, (B) invasion, and (C) survival were analyzed. Three independent experiments were carried out in quadruplicate.

$\mathrm{IU} / \mathrm{ml} \mathrm{M-CSF}$ for $24 \mathrm{~h}$. Then the effects of $10 \mu \mathrm{M}$ of LY29004 on proliferation, invasion, and survival were analyzed by the assay methods as described above. GM-CSF partially reversed growth inhibitory effects of LY29004 in A549 cells and almost completely reversed the effects in A924, A964, and MI-4 cells. M-CSF synergized the growth inhibitory effect of LY29004 in the cells (Fig. 6A). GM-CSF and M-CSF partially reversed invasion inhibitory effects of LY29004 in the cells (Fig. 6B). GM-CSF partially reversed the cytotoxic effect of LY29004 in A549, A924 and MI-4 cells and almost completely reversed
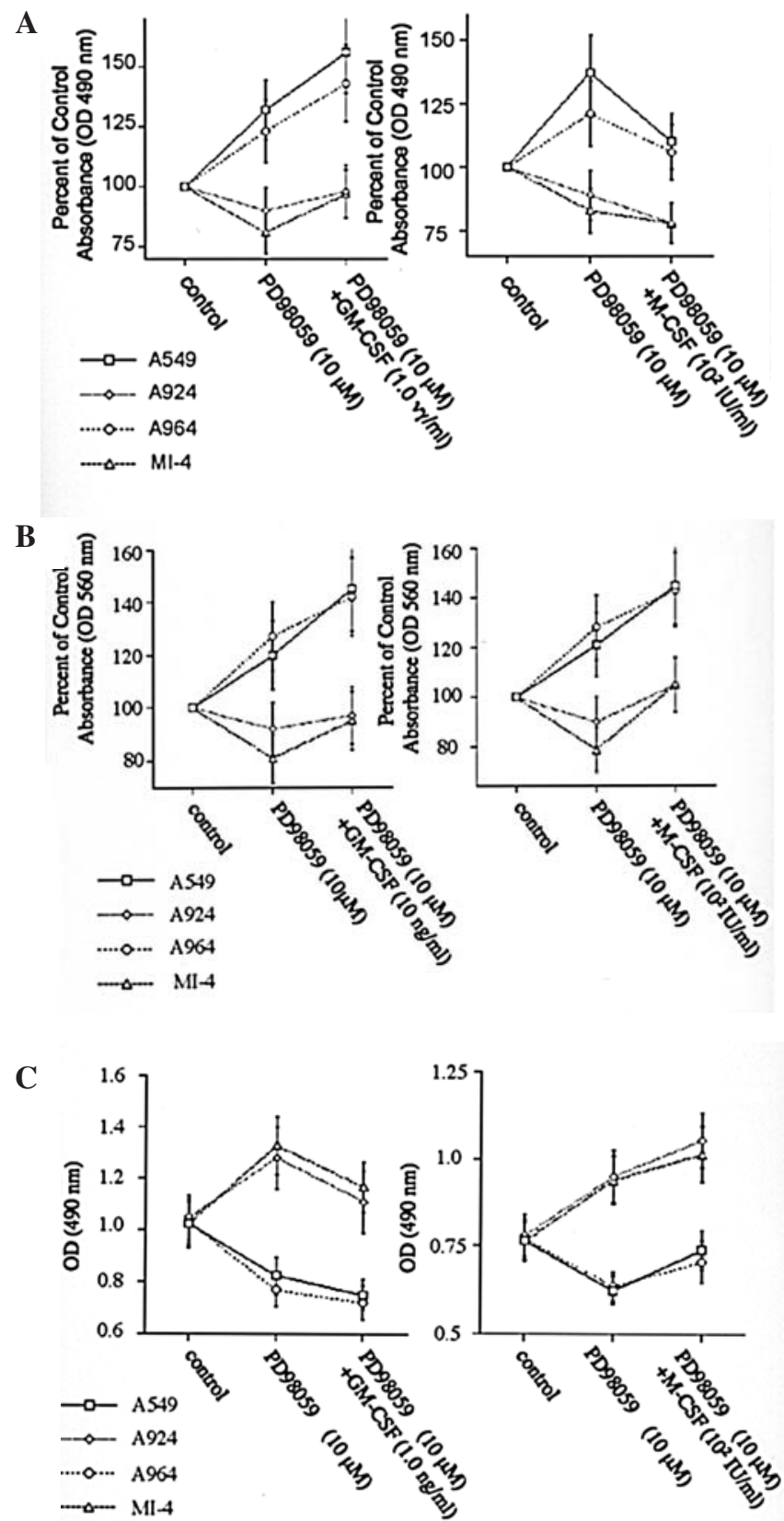

Figure 7. Effects of GM-CSF and M-CSF on the cells treated with PD98059. Cells were treated with $1.0 \mathrm{ng} / \mathrm{ml}$ of GM-CSF or $10^{2} \mathrm{IU} / \mathrm{ml}$ of M-CSF for $24 \mathrm{~h}$. After $48 \mathrm{~h}$, the effects of LY29004 on (A) proliferation, (B) invasion, and (C) survival were analyzed. Three independent experiments were carried out in quadruplicate.

it in A964 cells. M-CSF synergically increased the cell death in the cell lines (Fig. 6C). Three independent experiments were carried out in quadruplicate.

Effects of GM-CSF and M-CSF on the cells treated with PD 98059. Cells were treated with $1.0 \mathrm{ng} / \mathrm{ml} \mathrm{GM-CSF}$ or $10^{2} \mathrm{IU} / \mathrm{ml} \mathrm{M}$-CSF for $24 \mathrm{~h}$. Then the effects of $10 \mu \mathrm{M}$ PD98059 on proliferation, invasion and survival were analyzed by the assay methods as described above. GM-CSF synergized the growth stimulatory effect of PD98059 in A549, and A964 cells and almost completely reversed the growth inhibitory effect of PD98059 in A924 and MI-4 cells. M-CSF decreased 
A
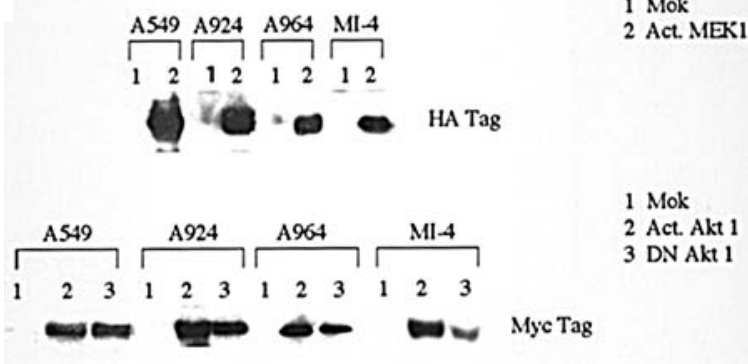

B
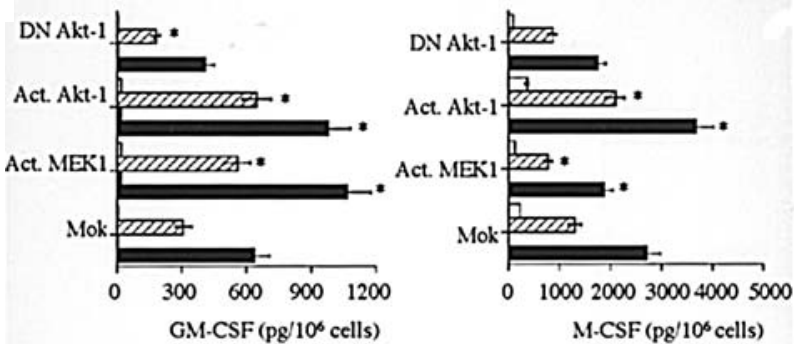

口 A549

ש. A924

ㅁ 996

口 $\mathrm{Ml}-4$

C

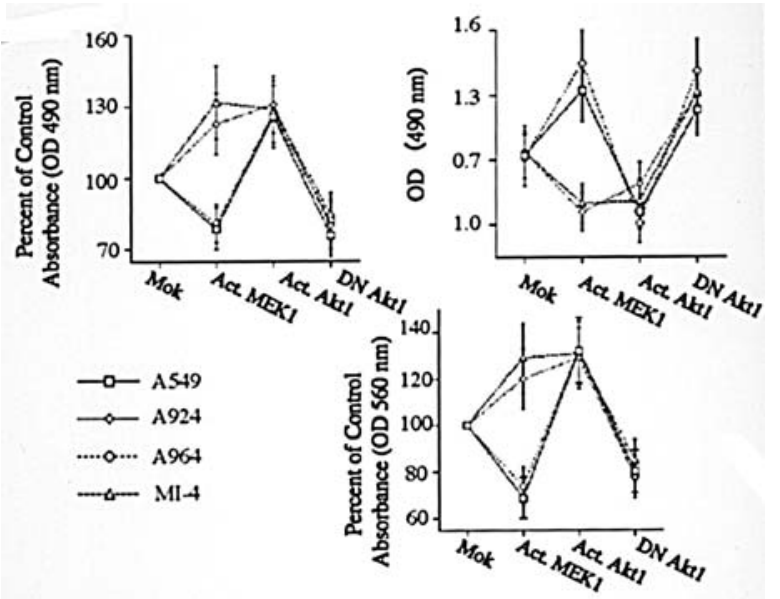

Figure 8. Effects of activation of Akt-1 and MEK1 on CSF production, cell growth, death and invasion. Active forms of human MEK1 and Akt1/PKB $\alpha$ cDNA, dominant negative (DN) mutant of $A k t 1 / P K B \alpha$ cDNA and empty expression vector (Mok) were transiently transfected into A924, A549, A964, and MI-4 cells. The transfected cells were analyzed for CSF production, proliferation, death and invasion. (A) Expression of Akt1 or DN Akt1 was detected by immunoblot analysis using anti-Myc tag antibody, and MEK1 using anti-HA tag antibody. (B) GM-CSF and M-CSF levels in the medium were measured. The values of GM-CSF and M-CSF in the conditioned medium were expressed in $\mathrm{pg} / 10^{6}$ cells. Three independent experiments were carried out in quadruplicate. ${ }^{*} \mathrm{P}<0.05$ vs. Mok (control). (C) Cell proliferation, cytotoxicity, and invasion assays were performed. Three independent experiments were carried out in quadruplicate.

the growth stimulatory effect of PD98059 in A549 and A964 cells and synergized the growth inhibitory effect of PD98059 in A924 and MI-4 cells (Fig. 7A). GM-CSF and M-CSF synergized the invasion promotion effect on PD98059 in A549 and A964 cells, whereas they partially reversed the inhibitory effect in A924 and MI-4 cells (Fig. 7B). GM-CSF partially reversed the cytotoxicity of PD98059 in A924, and
MI-4 cells and synergized the cytotoxicity in A549 and A964 cells. M-CSF enhanced the cytotoxicity of PD98059 in A924 and MI-4 cells and reversed the cytotoxicity once inhibited by PD98059 in A549 and A964 cells (Fig. 7C). Three independent experiments were carried out in quadruplicate.

Effects of activated Akt-1 and MEK1 on production of GM-CSF and $M-C S F$, cell growth, death and invasion. Cells were transiently transfected with active forms of human $M E K 1$ and $A k t 1 / P K B \alpha$ cDNA, dominant negative mutant of $A k t 1 / P K B \alpha$ cDNA and empty expression vector pUSEamp (+). Expression of Akt1 was detected by immunoblot analysis of cells transfected with activated or DN Aktl cDNA using anti-Myc tag antibody, and MEK1 with activated MEK1 cDNA using antiHA tag antibody. Mock transfectants transfected with empty expression vector did not show any band (Fig. 8A). Activation of MEK1 and Akt1 increased GM-CSF production by A924 and MI-4 cells, whereas DN Akt-1 suppressed the constitutive production of GM-CSF. Activation of MEK1 decreased constitutive production of M-CSF in A924 and MI-4 cells. Activation of Akt-1 increased M-CSF production in A924 and MI-4 cells, whereas DN Akt-1 suppressed the constitutive production of GM-CSF (Fig. 8B). Activation of MEK1 suppressed cell growth and invasion, and increased cell death in A549 and A964 cells, whereas the opposite effects were seen in A924 and MI-4 cells. Activation of Akt-1 enhanced cell growth and invasion and suppressed cell death in all the cell lines. DN Akt-1 expression was the opposite to the activated Akt-1 expression in each cell line (Fig. 8C). Three independent experiments were carried out in quadruplicate.

\section{Discussion}

Several studies have demonstrated the presence of an autocrine or paracrine growth loop for GM-CSF in nonhematopoietic tumor cells $(28,32,33)$. In addition, GM-CSF and M-CSF can stimulate the invasive capacity of human lung cancer cells (9). A924 and MI-4 constitutively produced abundant amount of GM-CSF and M-CSF, whereas A549 and A964 scarcely produced them. The biologic behavior and the regulatory mechanisms of the overproduction of GM-CSF and M-CSF by tumor cells are still unknown. Our results demonstrated that GM-CSF accelerates tumor growth and invasion, and M-CSF accelerates tumor invasion not growth in both CSF-producing cells (A924 and MI-4) and CSF-nonproducing cells (A549 and A964). These tumor cell-specific phenotypes by GM-CSF and M-CSF were mediated by MEK/ERK and PI3K/Akt signalings. Generally, constitutive MEK1 activation contributes to cell survival (20), migration (21), transformation of fibroblasts and epithelial cells (22). Inhibition of PI3K/Akt signaling blocks growth, promotes apoptosis, and enhances sensitivity of small-cell lung cancer cells to chemotherapy (34). Thus, MEK/ERK and PI3K/Akt are significantly important pathways for biologic behavior of lung cancer.

In this study, we first demonstrated that GM-CSF can activate PI3K/Akt, inducing tumor-specific behavior of lung cancer cells as is already reported in neutrophils $(35,36)$. Although M-CSF suppressed Akt activation immediately after administration in all cell lines, it gradually activated 
subsequently to maximize at the time points of 20-40 $\mathrm{min}$. M-CSF promotes cell survival through Akt/PKB in human monocyte (26). Pei et al reported that M-CSF promotes the invasive capacity of human lung cancer cells (10). Akt1 induces the invasive behavior of mammary epithelial cells with increased matrix metalloproteinase-2 expression (37). Our results show that M-CSF promotes invasiveness through activation of PI3K/Akt in lung cancer. In contrast, M-CSF rather inhibited tumor growth and survival in our cell lines. Lin et al reported that M-CSF accelerates the development of the primary tumors for invasiveness in vitro but not their growth (38), supporting that M-CSF is closely associated with a step in the metastatic spread not tumor growth of lung cancer. We are not abe to explain why M-CSF transiently inhibited phosphorylation of Akt at early time points in the cell lines. The transient inhibition of Akt is likely caused by a property of M-CSF not the culture condition or procedure because GM-CSF did not give such an effect.

GM-CSF up-regulated MEK/ERK signaling in CSFproducing cells (A924 and MI-4), whereas such signaling was down-regulated in CSF-non-producing cells (A549 and A964). However, the opposite regulation of MEK/ERK by GM-CSF commonly leads to acceleration of tumor growth and invasion in both groups of cell lines. Nguyen et al reported that expression of constitutively activated MEK1 in A549 cells led to activation of caspase- 3 and apoptosis (39). Our data also demonstrated that A549 cells transfected with activated MEK1 cDNA increases cell death, and inhibits cell growth and invasion. The roles of the MEK/ERK pathway in lung cancer may differ somewhat according to cell origin or phenotype. It is still unclear whether the opposite biologic behavior by MEK1 activation might be based on the ability to constitutively produce CSFs. M-CSF stimulates proliferation of macrophages through activation of ERK (40). However, it is still unknown whether the effects of M-CSF on tumor cellspecific phenotypes (e.g. tumor cell growth, survival and invasion) might be mediated by MEK/ERK signaling. In our study, M-CSF dose-dependently inhibited MEK/ERK in both groups of the cell lines, resulting in inhibition of the growth and survival, yet accelerated the invasion, suggesting that the $\mathrm{PI} 3 \mathrm{~K} /$ Akt signaling would be more dominant than MEK/ERK in the invasiveness stimulated by M-CSF.

Constitutive production of GM-CSF and M-CSF by A924 or MI-4 cells was suppressed by PI3K/Akt inhibition, but increased by activated Akt 1 expression. These results suggest that PI3K/Akt activation might accelerate tumor growth or invasion by an autocrine and paracrine growth loop for GMCSF and M-CSF. Activated MEK1 expression increased constitutive GM-CSF production in the cell lines and suppressed M-CSF production. We demonstrated that exogenous M-CSF enhances invasiveness of A924 and MI-4 cells. However, invasiveness of A924 or MI-4 cells was apparently promoted by MEK/ERK activation regardless of the decrease of M-CSF production, suggesting that the effect of GM-CSF might be more dominant than M-CSF in invasiveness of CSF-producing cells or that other factors except GM-CSF and M-CSF stimulating invasiveness might be induced by expression of activated MEK1.

Collectively, GM-CSF and M-CSF affected tumor-specific phenotypes through PI3K/Akt and MEK/ERK pathways in lung cancer. However, MEK/ERK pathway oppositely regulated tumor-specific behavior between CSF-producing cells and CSF-non-producing cells. To clearly elucidate the roles of CSFs in lung cancer, additional studies are necessary.

\section{References}

1. Teramachi M, Miyamoto N, Yamamoto Y, Sasaka T, Nakamura T and Kitamura F: A case of large cell carcinoma of the lung which is suspected of producing Granulocyte colonystimulating factor. J Jpn Respir Soc 30: 1327-1332, 1992.

2. Watanabe M, Ono K, Ozeki Y, Tanaka S, Aida S and Okuno Y: Production of granulocyte-macrophage colony-stimulating factor in a patient with metastatic chest wall large cell carcinoma. Jpn J Clin Oncol 28: 559-562, 1998.

3. Adachi N, Yamaguchi K, Morikawa T, Suzuki M, Matsuda I and Abe MK: Constitutive production of multiple colonystimulating factors in patients with lung cancer associated with neutrophilia. Br J Cancer 69: 125-129, 1994.

4. Kasuga I, Makino S, Kiyokawa H, Katoh H, Ebihara Y and Ohyashiki K: Tumor related leukocytosis is linked with poor prognosis in patients with lung carcinoma. Cancer 92: 2399-2405, 2001.

5. Mroczko B, Szmitkowski M and Czygier M: Granulocyte colony stimulating factor (G-CSF) in diagnosis and monitoring of non-small cell lung cancer (NSCLC). Pol Arch Med Wewn 103: 163-168, 2000.

6. Young MR, Charboneau S, Lozano Y, Djordjevic A and Young ME: Activation of the protein kinase a signal transduction pathway by granulocyte-macrophage colony stimulating factor or by genetic manipulation reduces cytoskeletal organization in Lewis lung carcinoma variants. Int J Cancer 56: 446-451, 1994

7. Uemura Y, Kobayashi M, Nakata H, Harada R, Kubota T and Taguchi H: Effect of serum deprivation on constitutive production of granulocyte-colony stimulating factor and granulocyte macrophage-colony stimulating factor in lung cancer cells. Int $\mathbf{J}$ Cancer 109: 826-832, 2004.

8. Filderman AE, Bruckner A, Kacinski BM, Deng N and Remold HG: Macrophage colony-stimulating factor (CSF-1) enhances invasiveness in CSF-1 receptor-positive carcinoma cell lines. Cancer Res 52: 3661-3666, 1992.

9. Pei XH, Nakanishi Y, Takayama K, Bai F and Hara N: Granulocyte, granulocyte macrophage, and macrophage colonystimulating factors can stimulate the invasive capacity of human lung cancer cells. Br J Cancer 79: 40-46, 1999.

10. Webb CP, Van Aelst L,Wigler MH and Woude GF: Signaling pathways in Ras-mediated tumorigenicity and metastasis. Proc Natl Acad Sci USA 95: 8773-8778, 1998.

11. Amundadottir LT and Leder P: Signal transduction pathways activated and required for mammary carcinogenesis in response to specific oncogenes. Oncogene 16: 737-746, 1998.

12. Blackhall FH, Pintilie M, Michael M, et al: Expression and prognostic significance of kit, protein kinase $\mathrm{B}$, and mitogen activated protein kinase in patients with small cell lung cancer. Clin Cancer Res 9: 2241-2247, 2003.

13. Oka H, Chatani Y, Hoshino R, et al: Constitutive activation of mitogen-activated protein (MAP) kinases in human renal cell carcinoma. Cancer Res 55: 4182-4187, 1995.

14. Sivaraman VS, Wang H, Nuovo GJ and Malbon CC: Hyperexpression of mitogen-activated protein kinase in human breast cancer. J Clin Invest 99: 1478-1483, 1997.

15. Albanell J, Codony-Servat J, Rojo F, et al: Activated extracellular signal-regulated kinases: association with epidermal growth factor receptor/transforming growth factor alpha expression in head and neck squamous carcinoma and inhibition by antiepidermal growth factor receptor treatments. Cancer Res 61: 6500-6510, 2001.

16. Ito Y, Sasaki Y, Horimoto M, et al: Activation of mitogenactivated protein kinases/extracellular signal-regulated kinases in human hepatocellular carcinoma. Hepatology 27: 951-958, 1998.

17. Gioeli D, Mandell JW, Petroni GR, Frierson HF Jr and Weber MJ: Activation of mitogen-activated protein kinase associated with prostate cancer progression. Cancer Res 59: 279-284, 1999. 
18. Handra-Luca A, Bilal H, Bertrand JC and Fouret P: Extracellular signal-regulated ERK-1/ERK-2 pathway activation in human salivary gland mucoepidermoid carcinoma: association to aggressive tumor behavior and tumor cell proliferation. Am J Pathol 163: 957-967, 2003.

19. Cohen C, Zavala-Pompa A, Sequeira JH, et al: Mitogen-actived protein kinase activation is an early event in melanoma progression. Clin Cancer Res 8: 3728-3733, 2002.

20. Ballif BA and Blenis J: Molecular mechanisms mediating mammalian mitogen-activated protein kinase (MAPK) kinase (MEK)-MAPK cell survival signals. Cell Growth Differ 12: 397-408, 2001.

21. Krueger JS, Keshamouni VG, Atanaskova N and Reddy KB: Temporal and quantitative regulation of mitogen-activated protein kinase (MAPK) modulates cell motility and invasion. Oncogene 20: 4209-4218, 2001.

22. Montesano R, Soriano JV, Hosseini G, Pepper MS and Schramek H: Constitutively active mitogen-activated protein kinase kinase MEK1 disrupts morphogenesis and induces an invasive phenotype in Madin-Darby canine kidney epithelial cells. Cell Growth Differ 10: 317-332, 1999.

23. Kawaguchi M, Kokubu F, Odaka M, et al: Induction of granulocyte-macrophage colony-stimulating factor by a new cytokine, ML-1 (IL-17F), via Raf I-MEK-ERK pathway. J Allergy Clin Immunol 114: 444-450, 2004.

24. Lee AW: Synergistic activation of mitogen-activated protein kinase by cyclic AMP and myeloid growth factors opposes cyclic AMP's growth-inhibitory effects. Blood 93: 537-553, 1999.

25. Lee HY: Molecular mechanisms of deguelin-induced apoptosis in transformed human bronchial epithelial cells. Biochem Pharmacol 68: 1119-1124, 2004.

26. Kelley TW, Graham MM, Doseff AI, et al: Macrophage colonystimulating factor promotes cell survival through Akt/protein kinase B. J Biol Chem 274: 26393-26398, 1999.

27. Pei XH, Nakanishi Y, Takayama K, Bai F, Kawasaki M and Hara N: G-CSF increases secretion of urokinase-type plasminogen activator by human lung cancer cells. Clin Exp Metastasis 16: 551-558, 1998.

28. Oshika Y, Nakamura M, Abe Y, et al: Growth stimulation of non-small cell lung cancer xenografts by granulocyte-macrophage colony-stimulating factor (GM-CSF). Eur J Cancer 34: 1958-1961, 1998.

29. Bruckner A, Filderman AE, Kirchheimer JC, Binder BR and Remold HG: Endogenous receptor-bound urokinase mediates tissue invasion of the human lung carcinoma cell lines A549 and Calu-1. Cancer Res 52: 3043-3047, 1992.
30. Tani K, Ozawa K, Ogura H, et al: Expression of granulocyte and granulocyte-macrophage colony-stimulating factors by human non-hematopoietic tumor cells. Growth Factors 3: 325-331, 1990

31. Harada R, Uemura Y, Kobayashi M, et al: Establishment and characterization of a new lung cancer cell line (MI-4) producing high levels of granulocyte colony stimulating factor. Jpn J Cancer Res 93: 667-676, 2002.

32. Miyagawa K, Chiba S, Shibuya K, et al: Frequent expression of receptors for granulocyte-macrophage colony-stimulating factor on human nonhematopoietic tumor cell lines. J Cell Physiol 143: 483-487, 1990.

33. Tachibana M, Miyakawa A, Tazaki H, et al: Autocrine growth of transitional cell carcinoma of the bladder induced by granulocyte-colony stimulating factor. Cancer Res 55: 3438-3443, 1995.

34. Krystal GW, Sulanke G and Litz J: Inhibition of phosphatidylinositol 3-kinase-Akt signaling blocks growth, promotes apoptosis, and enhances sensitivity of small cell lung cancer cells to chemotherapy. Mol Cancer Ther 1: 913-922, 2002.

35. Coffer PJ, Geijsen N, M'rabet L, et al: Comparison of the roles of mitogen-activated protein kinase kinase and phosphatidylinositol 3-kinase signal transduction in neutrophil effector function. Biochem J 329: 121-130, 1998.

36. Kamata N, Kutsuna H, Hato F, et al: Activation of human neutrophils by granulocyte colony-stimulating factor, granulocytemacrophage colony-stimulating factor, and tumor necrosis factor alpha: role of phosphatidylinositol 3-kinase. Int J Hematol 80: 421-427, 2004.

37. Park BK, Zeng X and Glazer RI: Akt1 induces extracellular matrix invasion and matrix metalloproteinase-2 activity in mouse mammary epithelial cells. Cancer Res 61: 7647-7653, 2001.

38. Lin EY, Nguyen AV, Russell RG and Pollard JW: Colonystimulating factor 1 promotes progression of mammary tumors to malignancy. J Exp Med 193: 727-740, 2001.

39. Nguyen TT, Tran E, Nguyen TH, Do PT, Huynh TH and Huynh H: The role of activated MEK-ERK pathway in quercetin-induced growth inhibition and apoptosis in A549 lung cancer cells. Carcinogenesis 25: 647-659, 2004.

40. Comalada M, Valledor AF, Sanchez-Tillo E, Umbert I, Xaus J and Celada A: Macrophage colony-stimulating factor-dependent macrophage proliferation is mediated through a calcineurinindependent but immunophilin-dependent mechanism that mediates the activation of external regulated kinases. Eur J Immunol 33: 3091-3100, 2003. 